\title{
Depression, Anxiety, and Stress among Rural South Indian Women-Prevalence and Correlates: A Community-Based Study
}

\author{
Manikandan Srinivasan ${ }^{1} \quad$ Mahendra M. Reddy ${ }^{2}$ \\ ${ }^{1}$ Division of Gastrointestinal Sciences, Wellcome Trust Research \\ Laboratory, Christian Medical College, Vellore, India \\ 2Department of Community Medicine, Sri Devaraj Urs Medical \\ College, Kolar, Karnataka, India \\ ${ }^{3}$ Department of Community Medicine, Jawaharlal Institute \\ of Postgraduate Medical Education and Research (JIPMER), \\ Puducherry, India \\ ${ }^{4}$ Department of Psychiatry, Jawaharlal Institute of Postgraduate \\ Medical Education and Research, Puducherry (JIPMER), India
}

Sonali Sarkar ${ }^{3} \quad$ Vikas Menon $^{4}$

\begin{abstract}
Address for correspondence Vikas Menon, MD, Department of Psychiatry, Jawaharlal Institute of Postgraduate Medical Education and Research (JIPMER), Puducherry 605008, India (e-mail: drvmenon@gmail.com).
\end{abstract}

J Neurosci Rural Pract 2020;11:78-83

\begin{abstract}
Background The burden of common mental disorders (CMDs) which includes depression, anxiety, and stress-related disorders are on the rise in India. Women in rural areas form one of the high-risk groups with respect to CMDs due to their compromised status of living.

Objective The aim of the study was to estimate the prevalence of depression, anxiety, and stress, and the predictors to depression among women in rural Puducherry.

Methods A community-based, cross-sectional study was performed in 2016, among women aged 18 to 59 years, residing in the rural area of Puducherry. Prevalence of CMDs was determined using the Depression Anxiety Stress Scale (DASS)-21. Using a systematic random sampling method, women were interviewed in their houses. The socio-demographic characteristics along with risk factors for depression were captured using a semi-structured proforma. A multivariable logistic regression model was used to determine the predictors of depression.

Results A total of 301 women were surveyed and their mean age (SD) was 34.9 (10.2) years. The prevalence of depression, anxiety, and stress was found to be 15\% (95\% Cl: $11.3-19.3), 10.6 \%$ (95\% Cl: $7.5-14.5)$, and 5\% (95\% Cl: 3-8), respectively.

Keywords

- anxiety

- depression

- mental disorder

- rural women

- stress

Multivariable analysis identified that lesser education and living separately/divorced to be significant predictors for depression in these women.

Conclusion About one in six adult women living in a rural area was found to be depressed, which is considerably high. This emphasizes the need for screening among women for common mental disorders in primary care settings, especially in rural areas so that early diagnoses happen and thus reduce the impact due to mental disability.
\end{abstract}

\section{Introduction}

Global estimates in 2015 showed that 322 million people were affected with depression. Globally, "depression" was also identified as the single largest contributor for years lived with disability (YLD). The country-level estimates

DOI https://doi.org/

$10.1055 / \mathrm{s}-0039-1700595$

ISSN 0976-3147. showed that India contributed to $18 \%$ of this global burden with approximately 57 million cases. ${ }^{1}$ Depression being a chronic debilitating condition, can impact a person's living in all spheres-family, societal, and work; thus requiring early identification and treatment. At the country level, the increasing burden of depression in its population can 
decrease workplace productivity and can have an impact over per capita gross domestic product (GDP). Depression can also lead to suicide and is a major contributor to suicide-related deaths. ${ }^{2}$

A recent National Mental Health Survey (NMHS) in India in 2015 to 16, reported the lifetime prevalence of common mental disorders (CMDs), which includes depression, anxiety, and stress-related disorders as $12.3 \%{ }^{3}$ The disease severity of CMDs range from mild to severe, and people with CMDs of less severe forms, continue their day-to-day activities without much disruption and thereby, do not get identified in the healthcare system. Among CMDs, depression had the highest lifetime prevalence of 5.1\%. Three Indian studies done among patients attending primary care settings showed the prevalence of CMDs ranging between 15 and 44\% and among patients identified with CMDs, 33 to $83 \%$ were found to be depressed..$^{4-6}$ Depression was shown to be associated with factors such as middle-aged population in the 40 to 49 years age group, female gender, lesser education, lower socioeconomic status (SES), experiencing domestic violence, and living separately/divorced. NMHS also reported that up to 22 to $33 \%$ of the population with chronic noncommunicable diseases, such as ischemic heart disease, diabetes mellitus, hypertension, stroke, and cancer, had concurrent depression. Suicide, a commonly coexisting condition with severe depression, was found to have following as its risk factors-age ranging between 40 and 49 years and women gender. ${ }^{3}$

In terms of disease burden, anxiety and stress-related disorders come next to depression with a lifetime prevalence of 3.1\%. Both, anxiety and stress-related disorders have risk factors similar to depression, such as female gender and age group of 40 to 49 years. Place of living was another important determinant for CMDs with people from rural and urban nonmetro background had comparable disease burden and was quite high. ${ }^{3}$ A recent study from Central India has shown the prevalence of CMDs in the rural women to be $22 \%,{ }^{7}$ which is twice the national level estimate of $12.3 \%{ }^{3}$ Thus, there exists heterogeneity in disease burden estimates of CMDs between the studies, possibly due to varying geographical locations that were studied. These evidence collectively show that women, particularly from a rural background were at higher risk for CMDs as they age, and emphasize the need for regional level studies and estimates among this high-risk population. Also, to the best of our knowledge, there are no previous studies reporting burden of CMDs among women from Puducherry. With this background, a community-based study was conducted to assess the burden of depression, anxiety, and stress in rural women between 18 and 59 years of age in Puducherry and also to identify the correlates of depression in them.

\section{Materials and Methods}

\section{Study Design and Setting}

This is a community based cross-sectional analytical study done in the rural field practice area of Jawaharlal Institute of Postgraduate Medical Education and Research (JIPMER), Puducherry, which includes four villages namely-Ramanathapuram, Thondamanatham, Pillayarkuppam, and Thuthipet. This area has a population of around 10,000 and agriculture is the predominant occupation for this population. People of this area receive their health care services from a Rural Health Centre (RHC), which functions under the Department of Preventive and Social Medicine (PSM), JIPMER. This study was done during February 2016, among women aged between 18 and 59 years. Elderly women (60 years and above) were excluded from this study as the study tool used did not cover this age group.

\section{Sampling Method}

Using nMaster software version 2.0, the sample size was calculated as 310 (assuming the prevalence of depression among women as $16 \%,{ }^{8}$ with absolute precision of $5 \%$ and a design effect of 1.5). This study was conducted in two of the randomly chosen villages-Pillayarkuppam and Thuthipet, with a total of approximately 747 houses (550 [73\%] houses in Pillayarkuppam and 197 [27\%] houses in Thuthipet). Based on proportionate to size method, the number of houses to be visited in Pillayarkuppam and Thuthipet was calculated as 226 and 84, respectively. To achieve the sample size, we systematically approached every alternate house and only one woman from each household, who is in the eligible age group for this study, was selected randomly (if more than one were eligible and were present at the time of data collection) and interviewed from each house, after obtaining the verbal consent. If the house was locked, it was visited the following day and if locked the next house was included in the study.

\section{Study Outcome}

We used Depression Anxiety Stress Scale (DASS)-21 questionnaire for capturing the primary outcomes-depression, anxiety, and stress and, a semi-structured proforma was used to capture socio-demographic characteristics and other factors, such as the presence of debts, history of domestic violence, and addictions (alcohol/tobacco) among family members. DASS-21 is a screening tool to measure depression, anxiety, and stress in the reference period of "past 1 week." ${ }^{\text {Ques- }}$ tions in each of these three domains are based on the symptoms that would be reported by patients with above specified illnesses. The responses were captured in a four point Likert's scale and the scores ranged between 0 and 42 . Using the author given cut-offs for DASS tool, participants were classified into with/without the outcome under study and a similar scoring pattern was used in previous Indian studies as well. ${ }^{10,11}$ We used the Tamil version of DASS-21, which was translated to provide a better understanding of the participants. English version of DASS-21 was initially translated into Tamil version, which was then back-translated into English by a subject expert. Two people not associated with the survey conducted a linguistic validation of this translated version. Finally, the original and back-translated versions were examined for conceptual equivalence. Data collection was done by trained MBBS interns, under the supervision of the postgraduate trainee. Ethical approval was obtained from the Departmental Ethics Review Board. 


\section{Statistical Analysis}

The primary outcomes were expressed as proportion of women identified with depression, anxiety, and stress along with 95\% confidence interval (CI). Further, the

Table 1 Sociodemographic characteristics of adult women from rural areas of Puducherry, $2015(N=301)$

\begin{tabular}{|c|c|}
\hline Sociodemographic characteristics & $N(\%)$ \\
\hline \multicolumn{2}{|l|}{ Age category (in years) } \\
\hline $18-20$ & $05(1.7)$ \\
\hline $20-29$ & $103(34.2)$ \\
\hline $30-39$ & 99 (32.9) \\
\hline $40-49$ & $59(19.6)$ \\
\hline $50-59$ & $35(11.6)$ \\
\hline \multicolumn{2}{|l|}{ Education } \\
\hline Illiterate & $48(16.0)$ \\
\hline $1-5$ & $29(9.6)$ \\
\hline $6-8$ & $54(17.9)$ \\
\hline $9-12$ & $129(42.9)$ \\
\hline Graduate and above & $41(13.6)$ \\
\hline \multicolumn{2}{|l|}{ Socio economic status ${ }^{\mathrm{a}}$} \\
\hline Class 1 & $11(3.7)$ \\
\hline Class 2 & $50(16.6)$ \\
\hline Class 3 & $83(27.6)$ \\
\hline Class 4 & $69(22.9)$ \\
\hline Class 5 & $88(29.2)$ \\
\hline \multicolumn{2}{|l|}{ Type of family } \\
\hline Nuclear & $162(53.8)$ \\
\hline Joint & $139(46.2)$ \\
\hline \multicolumn{2}{|l|}{ Marital status } \\
\hline Single & $32(10.6)$ \\
\hline Married & $235(78.1)$ \\
\hline Separated & $5(1.7)$ \\
\hline Widowed & $29(9.6)$ \\
\hline \multicolumn{2}{|l|}{ Having debts in the family } \\
\hline Yes & $173(57.5)$ \\
\hline No & $128(42.5)$ \\
\hline \multicolumn{2}{|l|}{$\begin{array}{l}\text { Presence of addiction among family } \\
\text { members (Tobacco/alcohol) }\end{array}$} \\
\hline Yes & $52(17.3)$ \\
\hline No & $249(82.7)$ \\
\hline \multicolumn{2}{|l|}{ Presence of chronic disease } \\
\hline Yes & $35(11.6)$ \\
\hline No & $266(88.4)$ \\
\hline \multicolumn{2}{|l|}{ Domestic violence in partner } \\
\hline Yes & $21(7.3)$ \\
\hline No & $280(92.7)$ \\
\hline
\end{tabular}

aBG Prasad Classification updated in January 2014. association between primary outcome-depression and the socio-demographic factors were tested using univariate and multivariable logistic regression analysis and expressed using odds ratio (OR) with $95 \% \mathrm{CI}$. Data were single entered using in EpiData v3.1, and analysis was done using EpiData Analysis version V2.2.2.178 and Stata software version 11.0.

\section{Results}

A total of 301 women were interviewed and the mean age (SD) of the population was 34.9 (10.2) years. Among the participants, 203 (67\%) were in the age group of 20 to 39 years, $170(56.5 \%)$ had at least 9 years of education, and 34 (11.3\%) belonged to the separated or widowed marital status category. Nearly 21 (7\%) out of 301 women, had experienced domestic violence in the past (-Table 1). Of the 301 surveyed, number of women who experienced depression, anxiety, and stress in the past 1 week were 45 (15\% [95\% CI: $11.3-19.3]), 32$ (10.6\%, [95\% Cl: 7.5-14.5]), and 15 (5\% [95\% CI: 3-8]), respectively ( - Table 2 ).

In the univariate analysis, the risk factors associated with depression in women were-having lesser years of education, being separated/widowed, and experiencing domestic violence. Further in multivariate regression analysis, the associated risk factors for depression were-women with lesser years of education and being separated/widowed with an odds ratio of 6.1 (95\% CI: 1.1-33.1) and 3.9 (95\% CI: 1.4-10.4), respectively. None of the factors studied had shown an association with anxiety and stress in both univariate and multivariate analyses (- Table $\mathbf{3}$ ).

\section{Discussion}

This community-based study has shown that $15 \%$ of adult women in a rural area studied, had experienced depressive symptoms. Risk factors associated with depression in these women were discordant marital life (living separated/widowed) and having lesser years of education. Also, women who experienced domestic violence had significantly higher odds of reporting depressive symptoms; however, this association lost its significance in multivariable analysis.

Table 2 Prevalence of depression, anxiety, and stress among adult women from rural areas of Puducherry, $2015(N=301)$

\begin{tabular}{|c|l|}
\hline Outcome variable $^{\text {a }}$ & $N(\%)$ \\
\hline Presence of depression & \\
\hline Yes & $45(14.9)$ \\
\hline No & $256(85.1)$ \\
\hline Presence of anxiety & $32(10.6)$ \\
\hline Yes & $269(89.4)$ \\
\hline No & \\
\hline Presence of stress & $15(5)$ \\
\hline Yes & $286(95)$ \\
\hline No & \\
\hline
\end{tabular}

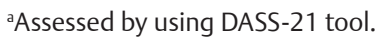


Table 3 Association between depression among adult women from rural areas of Puducherry $(N=301)$

\begin{tabular}{|c|c|c|c|c|}
\hline Study characteristics & Total & $\begin{array}{l}\text { Presence of } \\
\text { depression } N(\%)\end{array}$ & $\begin{array}{l}\text { Unadjusted odds ratio } \\
(95 \% \mathrm{Cl})\end{array}$ & $\begin{array}{l}\text { Adjusted odds ratio } \\
(95 \% \mathrm{Cl})\end{array}$ \\
\hline Age in years (mean [SD]) & $36.7(10)$ & - & $1.0(1.0-1.1)$ & $1.0(1.0-1.1)$ \\
\hline \multicolumn{5}{|l|}{ Education } \\
\hline Illiterate & 48 & $8(16.7)$ & $3.9(0.8-19.5)$ & $3.0(0.5-19.2)$ \\
\hline $1-5$ & 29 & $7(24.1)$ & $6.2(1.2-32.5)$ & $5.9(0.9-37.8)$ \\
\hline $6-8$ & 54 & $12(22.2)$ & $5.6(1.2-26.5)$ & $6.1(1.1-33.1)$ \\
\hline $9-12$ & 129 & $16(12.4)$ & $2.8(0.7-12.6)$ & $3.0(0.6-14.9)$ \\
\hline Graduate and above & 41 & $2(4.9)$ & Ref & Ref \\
\hline \multicolumn{5}{|l|}{ Socioeconomic status ${ }^{\mathrm{a}}$} \\
\hline Class 1 & 11 & $2(18.2)$ & Ref & Ref \\
\hline Class 2 & 50 & $7(14)$ & $0.7(0.1-4.1)$ & $0.5(0.1-3.7)$ \\
\hline Class 3 & 83 & $12(14.5)$ & $0.8(0.1-4.0)$ & $0.7(0.1-4.0)$ \\
\hline Class 4 & 69 & $13(18.8)$ & $1.0(0.2-5.4)$ & $0.6(0.1-3.8)$ \\
\hline Class 5 & 88 & $11(12.5)$ & $0.6(0.1-3.4)$ & $0.5(0.1-2.9)$ \\
\hline \multicolumn{5}{|l|}{ Type of family } \\
\hline Nuclear & 162 & $27(16.7)$ & $1.3(0.7-2.6)$ & $1.3(0.7-2.7)$ \\
\hline Joint & 139 & $18(12.9)$ & Ref & Ref \\
\hline \multicolumn{5}{|l|}{ Marital status } \\
\hline Single & 32 & $6(18.8)$ & $1.7(0.6-4.5)$ & $2.8(0.9-9.1)$ \\
\hline Married & 235 & $28(11.9)$ & Ref & Ref \\
\hline Separated/widowed & 34 & $11(32.4)$ & $3.5(1.6-8.1)$ & $3.9(1.4-10.4)$ \\
\hline \multicolumn{5}{|l|}{ Having debts in the family } \\
\hline Yes & 173 & $28(16.2)$ & $1.3(0.7-2.4)$ & $1.4(0.7-2.9)$ \\
\hline No & 128 & $17(13.3)$ & Ref & Ref \\
\hline \multicolumn{5}{|l|}{$\begin{array}{l}\text { Presence of addiction among } \\
\text { family members (Tobacco/ } \\
\text { alcohol) }\end{array}$} \\
\hline Yes & 52 & $11(21.2)$ & $1.7(0.8-3.6)$ & $1.4(0.6-3.6)$ \\
\hline No & 249 & $34(13.7)$ & Ref & Ref \\
\hline \multicolumn{5}{|l|}{ Presence of chronic disease } \\
\hline Yes & 35 & $9(25.7)$ & $2.2(1.0-5.1)$ & $1.8(0.7-4.7)$ \\
\hline No & 266 & $36(13.5)$ & Ref & Ref \\
\hline \multicolumn{5}{|c|}{ Domestic violence by a partner } \\
\hline Yes & 21 & $7(33.3)$ & $3.2(1.2-8.4)$ & $3.1(1.0-9.9)$ \\
\hline No & 280 & $38(13.6)$ & Ref & Ref \\
\hline
\end{tabular}

${ }^{\mathrm{a} B G}$ Prasad Classification updated in January 2014.

Two previous studies, the Chennai Urban Rural Epidemiology Study (CURES) done in Tamil Nadu, South India and another study from Vidharba, in Central India, has shown the prevalence of depression in females as $16.3 \%$ and $16.7 \%$ respectively. ${ }^{8,12}$ Though both of these studies used patient health questionnaire (PHQ-9) to screen depression, it is notable that the estimated prevalence of depression is comparable to our study which used DASS-21. Another recent study compared the variation in estimation of prevalence of depression using DASS-21 and PHQ-9 in the same group of subjects and results showed that DASS- 21 is a better case finding tool with higher specificity and, positive predictive value; whereas PHQ-9 is shown as a good screening tool because of its higher sensitivity and negative predictive value. ${ }^{13}$ Thus, our study by using DASS-21 could have classified fewer mildly depressed people as normal, thereby underestimating the prevalence.

This study identified the factors-living separated/widowed and having lesser years of education to be associated with depression. Both CURES study and study from Vidharba reported the same finding that people with lesser years of education and living separated/widowed had a higher chance of being depressed. ${ }^{8,12}$ However, both these studies 
additionally identified lower SES as an associated factor for depression and this association was not reflected in our study. One of the reasons we hypothesize here is Puducherry is a union territory and offers better support for economically backward people, through social welfare schemes and through a system of lesser taxation, when compared with the states. Second, people of Puducherry are at advantage for availing free or subsidized healthcare from the many medical colleges located here.

A recent systematic review on domestic violence in Indian women has shown that $41 \%$ of women reported domestic violence and another study from Bangladesh also reported domestic violence of $34 \%$ in women..$^{14,15}$ In contrary to these findings, only $7 \%$ of women of our study have reported domestic violence which might be an underreporting. Though we identified a significant association between domestic violence and depression in univariate analysis (OR: 3.2), the association turned out to be nonsignificant in multivariate analysis, which could be because of lesser reporting of domestic violence.

A study from Malaysia reported that $11.5 \%$ of diabetics had reported depression. In this study, the prevalence of depression in women, with and without chronic disease is $25.6 \%$ and $13.6 \%$, respectively ( $p$-value $=0.057) .{ }^{16}$ The probable reason for not having a significant association between depression and chronic disease, could be attributed to the fact that majority (69\%) of our study subjects are of 18 to 39 years age group, leaving out only a lesser proportion (31\%) in the age group of 40 to 59 years, in whom the burden of chronic diseases actually tend to be high.

The present study reported the prevalence of anxiety and stress in rural women as $10.6 \%$ and $5 \%$, respectively. A similar study done among Gujarati women belonging to the urban/semi-urban area has found the prevalence of anxiety and stress to be $35 \%$ and $26 \%$, respectively which is alarmingly high when compared with our estimates. ${ }^{17}$ The difference in prevalence estimates between the two aforementioned studies can be attributed to the existing differences in the study setting, with a former study from a rural setting, when compared with the latter one from an urban area. It is observed that among 45 women who reported depressive symptoms, 15 (35.6\%) and 10 (22.2\%) had concomitant anxiety and stress. Thus CMDs can often be coexistent and therefore, the process of screening for these diseases should be comprehensive. However, none of the risk factors studied showed significant association with either anxiety or stress.

This study has a few strengths. This is one among the few studies, providing a community-based estimate of depression among women of 18 to 59 years age group. We used DASS-21 as the study tool, which has good psychometric properties and it has been tested in many settings in India across wider age groups. ${ }^{18,19}$ Another potential strength for our study is, the interview was conducted by trained MBBS interns who provided better clarifications for the doubts that came up during the interview, which is not the case in other studies that usually use field research officers for data collection.
The study is not without limitations. As with other cross-sectional studies, the temporality for ascertaining causality cannot be made in this study. Since the sample size was based on primary outcome-the prevalence of depression, the study could be underpowered to identify the factors associated with depression. Since this study is a face-to-face interview, there could be hesitancy among women in discussing sensitive issues like domestic violence.

\section{Conclusion}

One in six rural women reported symptoms suggestive of depression. Women with less educational status, living separated/divorced, and being subjected to domestic violence had higher chances of being depressed. Thus, healthcare providers at primary care settings apart from providing routine healthcare should also elicit for aforementioned risk factors in rural women, so as to screen and provide treatment at the earliest.

\section{Authors' Contributions}

M.S. designed the data extraction sheet, collected and entered data. M.S. analyzed the data. M.S., M.M., and V.M. prepared the manuscript. M.S., S.S., M.M., and V.M. critically reviewed the manuscript. All authors approved the final version.

\section{Funding \\ None.}

\section{Conflict of Interest}

None declared.

\section{Acknowledgments}

The authors thank the community of JIRHC and MBBS interns for their support throughout the study.

\section{References}

1 World Health Organization, Depression and Other Common Mental Disorders: Global Health Estimates. Geneva, Switzerland; 2017 6-15

2 World Health Organization: Country Office for India, Depression in India: Let's talk. New Delhi, India; 2017:1-32

3 Gururaj G, Varghese M, Benegal V, et al. National Mental Health Survey of India, 2015-16: prevalence, patterns and outcomes. Bengaluru, National Institute of Mental Health and Neuro Sciences, NIMHANS. Publication no. 129, 2016;1-138

4 Pothen M, Kuruvilla A, Philip K, Joseph A, Jacob KS. Common mental disorders among primary care attenders in Vellore, South India: nature, prevalence and risk factors. Int J Soc Psychiatry 2003;49(2):119-125

5 Patel V, Araya R, Chowdhary N, et al. Detecting common mental disorders in primary care in India: a comparison of five screening questionnaires. Psychol Med 2008;38(2):221-228

6 Nambi SK, Prasad J, Singh D, Abraham V, Kuruvilla A, Jacob KS. Explanatory models and common mental disorders among patients with unexplained somatic symptoms attending a primary care facility in Tamil Nadu. Natl Med J India 2002;15(6):331-335

7 Soni A, Fahey N, Byatt N, et al. Association of common mental disorder symptoms with health and healthcare factors among women in rural western India: results of a cross-sectional survey. BMJ Open 2016;6(7):e010834 
8 Poongothai S, Pradeepa R, Ganesan A, Mohan V. Prevalence of depression in a large urban South Indian population-the Chennai Urban Rural Epidemiology Study (Cures-70). PLoS ONE 2009;4:e7185

9 Lovibond PF, Lovibond SH, Manual for the Depression Anxiety \& Stress Scales. 2nd ed. Sydney, Australia: Psychology Foundation; 1995

10 Yadav R, Gupta S, Malhotra AK. A cross sectional study on depression, anxiety and their associated factors among medical students in Jhansi, Uttar Pradesh, India. Int J Community Med Public Health 2016;3(5):1209-1214

11 Kumar SD. S KH, Kulkarni P, Siddalingappa H, Manjunath R. Depression, anxiety and stress levels among medical students in Mysore, Karnataka, India. Int J Community Med Public Health 2017;3:359-362

12 Shidhaye R, Gangale S, Patel V. Prevalence and treatment coverage for depression: a population-based survey in Vidarbha, India. Soc Psychiatry Psychiatr Epidemiol 2016;51(7):993-1003

13 Lambert SD, Clover K, Pallant JF, et al. Making sense of variations in prevalence estimates of depression in cancer: A co-calibration of commonly used depression scales using Rasch Analysis. J Natl Compr Canc Netw 2015;13(10):1203-1211
14 Kalokhe A, Del Rio C, Dunkle K, et al. Domestic violence against women in India: a systematic review of a decade of quantitative studies. Glob Public Health 2017;12(4):498-513

15 Nasreen HE, Kabir ZN, Forsell Y, Edhborg M. Prevalence and associated factors of depressive and anxiety symptoms during pregnancy: a population based study in rural Bangladesh. BMC Womens Health 2011;11:22

16 Kaur G, Tee GH, Ariaratnam S, Krishnapillai AS, China K. Depression, anxiety and stress symptoms among diabetics in Malaysia: a cross sectional study in an urban primary care setting. BMC Fam Pract 2013;14:69

17 Patel PA, Patel PP, Khadilkar AV, Chiplonkar SA, Patel AD. Impact of occupation on stress and anxiety among Indian women. Women Health 2017;57(3):392-401

18 Iqbal S, Gupta S, Venkatarao E. Stress, anxiety and depression among medical undergraduate students and their sociodemographic correlates. Indian J Med Res 2015;141(3): 354-357

19 Rao S, Ramesh N. Depression, anxiety and stress levels in industrial workers: A pilot study in Bangalore, India. Ind Psychiatry J 2015;24(1):23-28 